\title{
Holothuria Arenicola as Promising Material for Therapeutic Drugs
}

\author{
Sohair R Fahmy* \\ Department of Zoology, Faculty of Science, Cairo University, Giza, Egypt
}

Received: February 10, 2018; Accepted: March 14, 2018; Published: March 19, 2018

*Corresponding author: Sohair R Fahmy, Department of Zoology, Faculty of Science, Cairo University, Giza, Egypt, E-mail: sohairfahmy@gmail.com

\begin{abstract}
Marine invertebrates have become attractive as nutraceutical and functional foods and as a source material for the development of therapeutic drugs. The bioactivity of echinoderm, Holothuria arenicola extracts and their secondary metabolites has been identified by researchers as a promising potential rich source of natural drugs. $H$. arenicola is rich in several phenolic compounds, amino acids, alkaloids and other important nutraceutical compounds. H. arenicola extract has been shown to produce promising antiulcerogenic efficacy that attributed to its high content of chlorogenic acid. The health benefits of $H$. arenicola are associated with its antioxidant, antifibrotic and antimicrobial effects. H. arenicola extract induced an apparent arrest in the progression of collagen deposition in the cholestatic animals which may be a consequence of the increased mass of regenerated liver cells.

The previous work showed that the antibacerial efficacy of H. arenicola body wall extract may be due to its content of polyphenolic compound especially quinine, saponins and terpenoid. Thus, this review aims to elaborates and analyze the role of $H$. arenicola in the modulation of several organ-specific diseases.
\end{abstract}

Key words: Holothuria arenicola; Anti-ulcerogenic; Antifibrotic; Anti-microbial; Antioxidants

\section{Introduction}

Marine invertebrates constitute one of the major groups of marine organisms from which a wide range of natural products have been devised [1]. However, there is increasing interest in the bioactivity of echinoderms extracts and their secondary metabolites. The consumption of sea cucumbers is thought to boost the immune system and to have aphrodisiac properties. They are gelatinous marine resources that are shaped like a cucumber that feed on microscopic algae, absorbing nutrients from the organic matter [2]. It is considered as "sea ginseng" because of its known medicinal properties aside from its nutritional value. The therapeutic use of the sea cucumbers for healing is established, where they were used for joint pain, tendonitis, and sprains [3]. Sea cucumber extracts usually showed multiple biological activities such as wound healing and antimicrobial, anticancer, and immunomodulatory [4, 5]. They are also remarkably rich in vitamins, trace elements, and polysaccharides (chondroitin sulfate), which reduce arthritis pain, inhibit viral activities, and saponin glycosides that inhibit cancer activities [3].

Holothuria arenicola Semper, 1868 (Figure 1) is distinctive

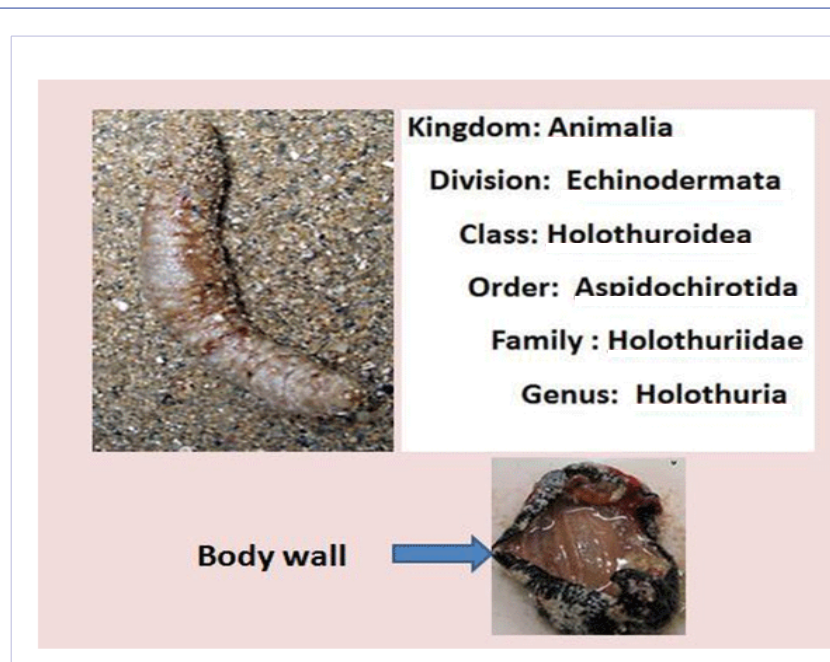

Figure 1:External feature of Holothuria arenicoloa

burrowing holothurians that are very common throughout the tropical regions of the world and it was one of the best known tropical shallow water species. The specific name arenicola Semper, 1868 is universally accepted, and has been used in a large number of systematic and ecological publications. In Egypt, Holothuria arenicola is distributed along the Alexandrian Mediterranean coast [6]. In $1984 \mathrm{H}$. arenicola was recorded for the first time on the Egyptian Mediterranean coast [7]. In 1998, small scale sea cucumber fishery began in Egypt in the southern part of the Red Sea. Later in the year of 2000, the sea cucumber fishery excelled greatly as a result of the high demand for the sea cucumber due to its consumption as a food newly introduced in Egypt and for exportation purposes. During those years Egypt has become one of the most important countries supplying the sea cucumber [8]. Sea cucumbers are well known to exert many beneficial effects on human health.

\section{Nutritional compounds of Holothuria arenicoloa}

Sea cucumber is an attractive bioactive source due to the presence of several bioactive compounds with therapeutic properties. Nutrition content of the $\mathrm{H}$. arenicoloa plays an essential function in its medicinal, nutritional, and therapeutic properties. High-performance liquid chromatography analysis of $\mathrm{H}$. arenicoloa revealed the presence of five non-volatile phenolic compounds [9] (Figure, 2). Chlorogenic acid was the 


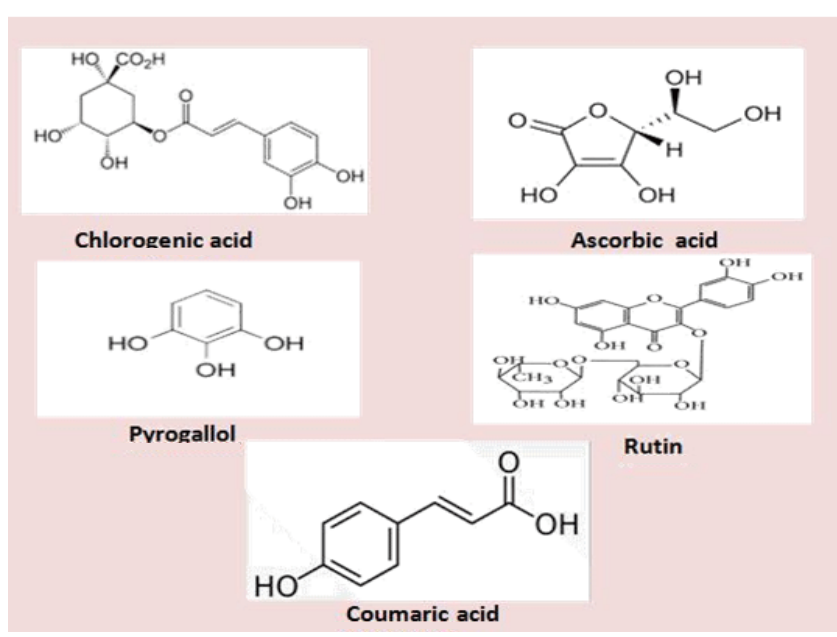

Figure 2:Chemical structure of the $H$. arenicoloa body wall phenolic compounds

major component (89.66\%), whereas ascorbic acid $(0.077 \%)$ was the minor component. Other components, such as pyrogallol $(1.88 \%)$, rutin $(1.06 \%)$ and coumaric acid $(1.23 \%)$ were also recorded. Presence of active phenolic compounds in the body wall of the sea cucumbers, $\mathrm{H}$. arenicoloa may be due to phenolicrich materials such as phytoplankton and particles derived from degrading marine macroalgae which are the main sources of food for sea cucumbers [10]. Phenolic compounds are very important antioxidant compounds [11], due to their redox properties which play an important role as free radical scavengers, reducing agents, quenchers of singlet oxygen and complexes of pro-oxidant metals [12]. Feng et al. [13] has been reported that chlorogenic acid is one of the most abundant polyphenols in the human diet that has been known to decrease the incidence of chemical carcinogenesis in several animal models of cancer. It is an important component of coffee [14]. The major polyphenol in coffee is CGA. CGA is an ester formed from cinnamic acids and quinic acid and is also known as 5-0-caffeoylquinic acid (5-CQA) (IUPAC numbering) or 3-CQA (pre-IUPAC numbering) [15]. It was demonstrated that CGA exert many biological activities such as antibacterial, antioxidant, and anticarcinogenic activities, particularly hypoglycemic and hypolipidemic effects [16-19].

The potential hepatoprotective effect of chlorogenic acid in several animal models of liver injury was reported [12, 9]. Chemical screening of the $\mathrm{H}$. arenicoloa body wall and coelomic fluid showed presence of other important bioactive compounds which exhibit numerous medicinal benefits and health functions, especially flavonoids, alkaloids, tannins, quinones, saponins, proteins and amino acids [20]. The use of H. arenicoloa in the traditional medicine may originate from its ability to regenerate body wall after being cut up [21]. In addition, Bordbar et al. [22], reported that the health benefits of sea cucumbers are associated with the presence of bioactive components such as saponins, glycosaminoglycans, sterols, cerberosides, peptides, sulfated polysaccharides, and essential fatty acids.

\section{Antiulcerogenic effects of $\mathrm{H}$. arenicoloa}

Peptic ulcer is the most prevalent disease among the gastrointestinal diseases in most part of the world. Gastric ulcer develops because of several endogenous and exogenous factors [23]. It results as a consequence of impaired balance between gastro-protective factors such as mucus, bicarbonate and prostaglandins, and gastro-destructive substances [24]. The incidence varies with the age, gender, geographical location and is associated with severe complications including hemorrhages, perforations, gastrointestinal obstruction, and penetration [25]. Under normal conditions a large number of defense mechanisms prevent local damage and maintain structural and functional mucosal integrity [26].

Traditional medicines have been used to prevent or treat gastric ulcers for a long time. Accordingly, many natural products have been examined for their anti-ulcerogenic effects $[27,28]$.

$H$. arenicola extract has been shown to produce promising antiulcerogenic efficacy that attributed to its high content of chlorogenic acid (CGA) [29]. Gastric ulcer lesion usually occurred due to increased gastric acidity secretion [30]. Most therapeutic agents exert their actions through inhibition of the gastric acid secretion [31]. H. arenicola induced marked improvement in gastric acid volume as compared to ranitidine (RAN) in rat model of gastric ulcer [29]. Gastric acid decimation by ranitidine is attributed to its ability to antagonize the binding of histamine to the $\mathrm{H} 2$ receptor on the parietal cells [32]. H. arenicola may be interferes with the gastric acid secretion and eliciting gastro protection via an adaptive mechanism. These findings indicate that the $H$. arenicola probably acts by inhibiting H2-receptor leading to blockade of histamine release whose stimulatory action on gastric acid secretion via $\mathrm{H} 2$-receptor, has been well reported [33]. It has been reported that CGA exert inhibitory effect on mast cell activation and subsequently histamine release [34]. Thereby, H. arenicola may decrease gastric acid secretion due to inhibition of histamin secretion as a result of its high content of CGA.

Gastric ulceration is a benign lesion on the mucosal epithelium upon exposure of the stomach to excess acid and aggressive pepsin activity [35]. Fahmy et al. [29] showed that $H$. arenicola exert significant improvement in gastric ulcer index as

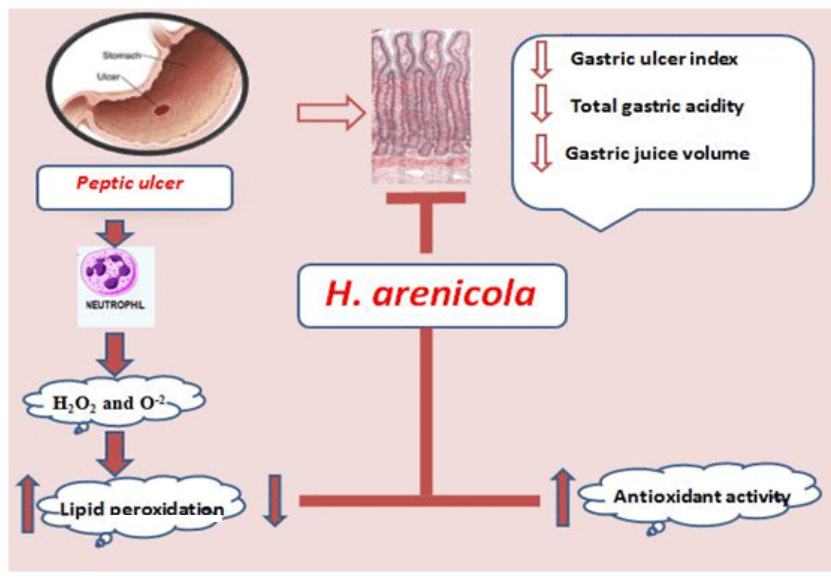

Figure 3: Schematic diagram showing antiulcerogenic mechanism of H. Arenicola body wall extract on some gastric indices 
compared to the standard drug RAN (Figure 3). H. arenicola may stimulate gastric mucosal cellular growth and repair by the same mechanism of wound healing. Indeed, the damage of the gastric mucosa is also related to the increase in neutrophil infiltration into ulcerated tissues. These neutrophils inhibit ulcer healing mediated lipid peroxidation through the release of cytotoxic factors such as superoxide and hydrogen peroxide. It was reported that RAN caused significant inhibition of neutrophil activation and gastric acid secretion [36]. H. arenicola may stimulate gastric mucosal cellular growth via inhibition of neutrophil activation. This mechanism can be supported by the study of Shimoyama et al. [37] and Zatorski et al. [38], who reported that CGA treatment blocked the influx of neutrophils into the gastric tissue. Other studies have also shown that CGA inhibits neutrophil recruitment into inflammatory tissues $[39,40]$.

Moreover, the anti-ulcerogenic effects of $H$. arenicola may be due to its antioxidant effect $[41,29]$. $H$. arenicola provided a marked suppression of oxidative damage through excellent radical scavenging activity to DPPH radical. Moreover, many dietary polyphenols are antioxidants, and the possibility exists that they protect against oxidative damage by directly neutralizing reactive oxidants [42]. The body wall of the sea cucumbers contains high amounts of phenolic compounds [43], which may exert scavenging activities by donating a hydrogen atom from their phenolic hydroxyl groups [11]. Thereby, H. arenicola may be an effective source of direct precursors for salvage glutathione reduced (GSH) biosynthesis.

The enhancement of the GSH level by the H. arenicola could be due to either its effect on the de novo synthesis of glutathione, its regeneration, or both [44]. Moreover, H. arenicola may act directly and scavenges the reactive oxygen species (ROS) derived by oxidation-reduction cycle with the cell or it may work in union with the existing antioxidant compounds and helps to prevent their loss during the ulcer oxidative injury.

Fahmy et al. [29] also showed that $H$. arenicola induced significant enhancement in the activities of GST, CAT and SOD antioxidant enzymes to prevent the accumulation of excessive free radicals and protect stomach from ulcer formation, suggesting that the anti-ulcerogenic effect of $H$. arenicola against oxidative stress induced injury might be involved in decreasing lipid peroxide generation and stimulating antioxidant enzyme. Fahmy et al. [29] proved that $H$. arenicola may overpower gastric ulcer onslaught by suppressing the formation of ROS and protecting the antioxidant machinery. Moreover, the induction of the antioxidant enzymes by the $H$. arenicola represents a promising preventive strategy as a bifunctional inducer, along with the enhancement of antioxidant system enzymes which affords protection against cellular damage and inhibits ulcer promotion.

\section{Antifibrotic effects of $\boldsymbol{H}$. arenicola}

Chronic liver disease is an important cause of morbidity and mortality and represents a major health problem worldwide [45].The high prevalence of chronic liver diseases in Egypt has led to increasing numbers of Egyptian patients suffering from end-stage liver disease [46]. Obstructive jaun $\neg$ dice, a frequently observed condition caused by obstruction of the common bile duct or its flow may end up with serious complications like hepatic failures [47]. Cholestatic liver fibrosis, characterized by excessive accumulation of extracellular matrix (ECM) proteins [48]. Cholestasis represents the consequence of impaired bile formation and generally caused by conditions that the enterohepatic circulation is interrupted and bile acids accumulate within the liver [49]. Mainly inflammatory cell infiltration, hepatocyte necrosis, and liver fibrosis are the main pathological features of cholestasis [50]. Retention of hydrophobic bile salts within the hepatocytes during cholestasis leads to apoptosis and necrosis [51]. Oxidative stress (OXS) and inflammatory injuries are the most important pathogenic events in cholestatic liver injury $[52,9]$.

Liver fibrosis, which etiologically and pathogenitically resembles the biliary fibrosis in the human beings can be induced by bile duct ligation and [53]. Several potential therapies for fibrosis have been identified in previous preclinical studies. These include interruption of matrix deposition and hence inhibition of collagen synthesis [54]. For the therapeutic strategies of liver injury and disease, it is important to find antioxidant compound that are able to block liver injuries through free radicals generated due to toxic chemicals. During the course of evolution, many invertebrates have established as a selective advantage by endogenous production of protective chemicals [55]. It was demonstrated that $H$. arenicola exerted an apparent arrest in the progression of collagen deposition in the cholestatic animals which may be a consequence of the increased mass of regenerated liver cells [9] This give an additional support that $H$. arenicola are able to condition the hepatocytes, accelerate regeneration of parenchyma cells, protect against membrane fragility and hence decrease leakage of the enzymes into circulation.

Acceleration in albumin synthesis may be another mechanism by which $H$. arenicola extract exert its antifibrotic efficacy [9]. Awang [56] has been reported that stimulation of albumin synthesis has been advanced as a contributory hepatoprotective mechanism which accelerates the regeneration process and the production of liver cells [56]. It was reported that oxidative stress occurs during cholestasis plays a role in cholestasis induced liver fibrosis [57]. Tissues and cells would be subjected to oxidative injuries when large quantities of inner free radicals are generated or the activities of antioxidant system deteriorate. Accordingly, antioxidant therapy represents a potential strategy to prevent liver injury and fibrosis. Treatment with $H$. arenicola normalized the antioxidant levels during cholestasis through its rich of polyphenolic compounds especially chlorogenic acid that has the ability to scavenge free radicals. Wang et al. [58] proved that chlorogenic acid decreased malondialdehyde (MDA) contents in liver while increased activities of antioxidant enzymes.

\section{Antimicrobial effects of $\boldsymbol{H}$. arenicola}

Several drug discovery projects have screened for echinoderms for antibiotic activities. Moreover, anti-fungal, anti-bacterial, antithrombotic, anti-malarial, anti-protozoa and anti-virus effects have been reported from some sea cucumber 
isolated compounds [59]. Many investigators reported the in vitro antibacterial and antifungal activities of Holothuria leucospilota body wall and coelomic fluid [60,61]. Fahmy et al. [20] proved the Body wall extract of the H. arenicola showed a broad spectrum antibacterial activity against Staphylococcus aureus and Escherichia coli. The antibacterial potency of the H. arenicola may be due to their antimicrobial components, flavonoids, alkaloids, tannins, quinines and saponins. It was reported that these active constituents have antibacterial characteristics [62].

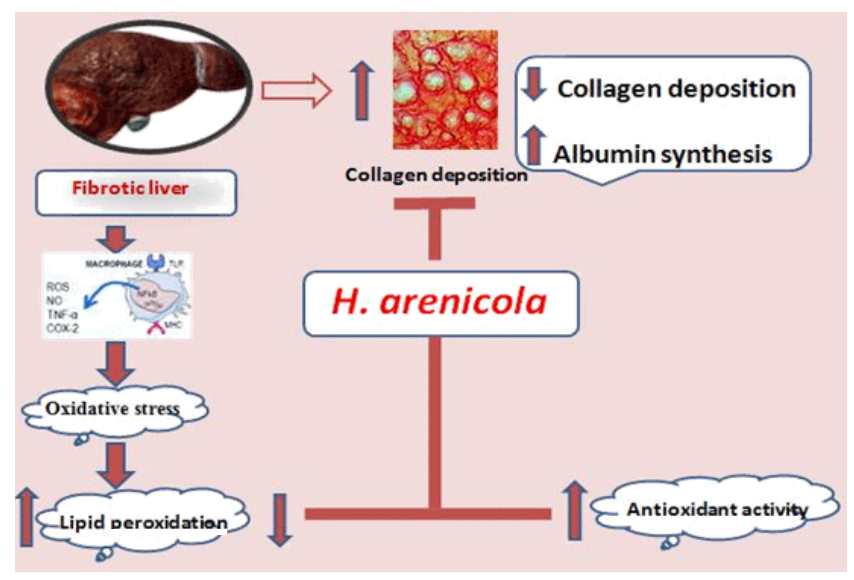

Figure 4: Schematic diagram showing antifibrotic mechanism of H. Arenicola body wall extract

Sepsis, a systemic inflammatory response syndrome (SIRS) induced by infection, is accompanied by the presence of bacteria [63]. Abundant evidence shows that CLP-induced sepsis with acute supportive peritonitis is a typical sepsis model with G-bacteria as the predominant infection source [64]. In a study by Fahmy et al. [20], the antimicrobial effects of H. arenicola was examined using rat model for cecal ligation and puncture (CLP) in which $200 \mathrm{mg} / \mathrm{kg}$ b.wt of the methanolic extract of $\mathrm{H}$. arenicola was used. The results showed that $\mathrm{H}$. arenicola body wall extract successfully increased survival rate of septic rats to $66.7 \%$ through its antibacterial activity.

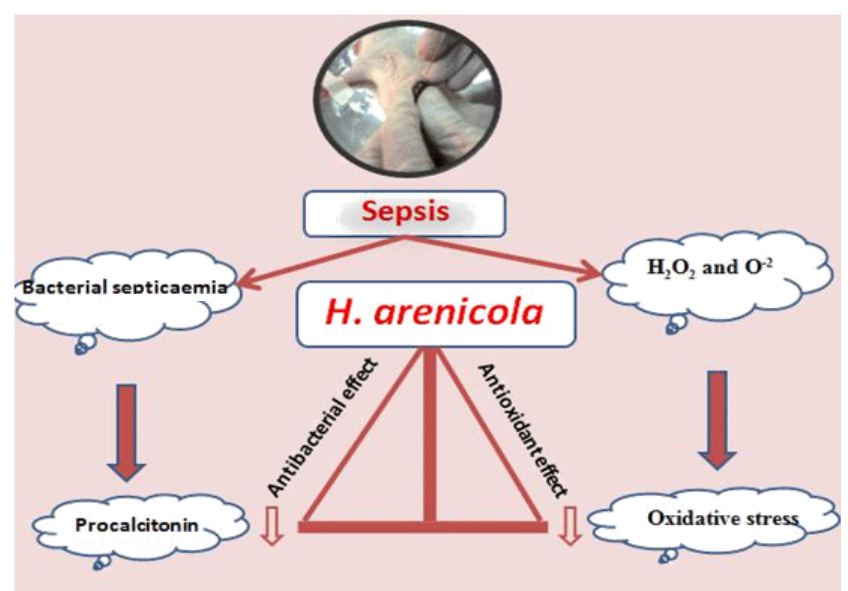

Figure 5: Schematic diagram showing antiseptic mechanism of H. Arenicola body wall extract
Procalcitonin (PCT), the precursor for the hormone calcitonin (CT) is a biomarker that exhibits greater specificity than other proinflammatory markers (cytokines) in identifying patients with sepsis and can be used in the diagnosis of bacterial infections [65] (Figure 5). Usually, PCT used to guide antibacterial therapy as a surrogate biomarker [66]. Fahmy et al. [20] showed that treatment of septic rats with H. arenicola body wall extract succeed to normalize the PCT level which may be due to their antimicrobial constituents. Accordingly, antibacerial of $\mathrm{H}$. arenicola body wall extract may be due to its content of polyphenolic compound especially quinine, saponins and terpenoid that show antibacterial characteristics [20].

\section{Conclusion}

The Present review shows some important therapeutic applications of $\mathrm{H}$. arenicola extract. The major health beneficial properties of $\mathrm{H}$. arenicola, which can give promising therapeutic application has been discussed in this review article. Antioxidant, antiulcerogenic, antimicrobial and antifibrotic activities are the major medicinal properties of the $\mathrm{H}$. arenicola demonstrated in different studies. High polyphenolic compound especially chlorogenic acid, quinine, saponins and terpenoid constituents are the most important therapeutic constituents of $\mathrm{H}$. arenicola extract. This review represents an important document about the beneficial effects of $\mathrm{H}$. arenicola extract that may qualify this extract for further studies and application in the future.

\section{References}

1. Jimenez J T, Sturdikova M, Studik E. Natural products of marine origin and their perspectives in the discovery of new anticancer drugs. Acta Chimica Slovaca 2009;2(2):63-74.

2. Conand C. The Fishery Resources of Pacific Island Countries. Part 2: Holothurians, FAO Fisheries Technical Paper 272.2; Food and Agriculture Organization of the United Nations: Rome, Italy, 1990; p. 143.

3. Hamel JF, Mercier A. "Synchronous gamete maturation and reliable spawning induction method in holothurians," in Advances in Sea Cucumber Aquaculture and Management, A. Lovatelli, C. Conand, S. Purcell, S. Uthicke, J.-F.Hamel, and A. Mercier, Eds., FAO Fisheries Technical Reports No. 463, FAO, Rome, Italy, 2004.

4. Ridzwan BH, Kaswandi MA, Azman Y, Fuad M. Screening for antibacterial agents in three species of sea cucumbers from coastal areas of Sabah. Gen. Pharmacol. 1995;26(7):1539-1543.

5. Tian F, Zhang X, Tong Y, Yi Y, Zhang S, Li L, et al. PE, a new sulfated saponin from sea cucumber, exhibits anti-angiogenic and anti-tumor activities in vitro and in vivo. Cancer Biol. Ther. 2005;4(8): 874-882.

6. Abdel Razek FA, Abdel Rahman SH, Moussa RM, Mena MH, El-Gamal MM. Captive Spawning of Holothuria arenicola (Semper, 1868) from Egyptian Mediterranean Coast. Asian Journal of Biological Sciences. 2012; 5(8): 425-431. DOI: 10.3923/ajbs.2012.425.431

7. Shoukr FA, Mona MH, Abdel Hamid ME. Holothurians (Echinodermata: Holothuroidea) from some Egyptian shores. Bulletin of the Faculty of Sciences of the Zagazig University. 1984;6:662-682.

8. Ahmed MI. Taxonomic and fishery stock status of sea cucumber in the Egyptian Red Sea. M. Phil. Thesis, Hull University, Hull, UK. 2006. 
9. Fahmy SR. Anti-fibrotic effect of Holothuria arenicola extract against bile duct ligation in rats. BMC Complementary and Alternative Medicine. 2015;15:14. doi: 10.1186/s12906-015-0533-7

10. Althunibat OYR, Hashim B, Taher M, Daud JM, Ikeda MA, Zali BI. In vitro antioxidant and antiproliferative activities of three Malaysian sea cucumber species, European Journal of Scientific Research. 2009;37:376-387.

11. Mustafa RA, Abdul Hamid A, Mohamed S, Bakar FA. Total phenolic compounds, flavonoids, and radical scavenging activity of 21 selected tropical plants. Journal of Food Science. 2010;75(1):28-35. DOI: 10.1111/j.1750-3841.2009.01401.x

12. Xu Y, Chen J, Yu X, Tao W, Jiang F, Yin Z, et al. Protective effects of chlorogenic acid on acute hepatotoxicity induced by lipopolysaccharide in mice. Inflamm Res. 2010;59(10):871-877. DOI: 10.1007/s00011010-0199-z

13. Feng R, Lu Y, Bowman LL, Qian Y, Castranova V, Ding M. Inhibition of activator protein-1, NF-B, and MAPKs and induction of phase 2 detoxifying enzyme activity by chlorogenic acid. J Biol Chem. 2005;280(30):27888-27895. DOI: 10.1074/jbc.M503347200

14. Olthof MR, Hollman PCH, Katan MB. Chlorogenic acid and caffeic acid are absorbed in humans. Journal of Nutrition. 2001;131(1):66-71.

15. Clifford MN. Chlorogenic acids and other cinnamates-nature, occurrence, dietary burden, absorption and metabolism. Journal of the Science of Food and Agriculture. 2000;80:1033-1043.

16. Kono Y, Kobayashi K, Tagawa S, Adachi K, Ueda A, Sawa Y, et al. Antioxidant activity of polyphenolics in diets. Rate constants of reactions of chlorogenic acid and caffeic acid with reactive species of oxygen and nitrogen. Biochimica et Biophysica Acta-General Subjects. 1997;1335(3):335-342.

17. Kasai H, Fukada S, Yamaizumi Z, Sugie S, Mori H. Action of chlorogenic acid in vegetables and fruits as an inhibitor of 8-hydroxydeoxyguanosine formation in vitro and in a rat carcinogenesis model. Food and Chemical Toxicology. 2000;38(5):467-471.

18. dos Santos, Almeida MC, Lopes NP, de Souza GE. Evaluation of the anti-inflammatory, analgesic and antipyretic activities of the natural polyphenol chlorogenic acid. Biological and Pharmaceutical Bulletin. 2006;29(11):2236-2240.

19. Bassoli BK, Cassolla P, Borba-Murad GR, Constantin J, SalgueiroPagadigorria CL, Bazotte RB, et al. Chlorogenic acid reduces the plasma glucose peak in the oral glucose tolerance test: effects on hepatic glucose release and glycaemia. Cell Biochemistry and Function. 2008;26(3):320-328. DOI: 10.1002/cbf.1444

20. Fahmy SR, Soliman AM, Sayed AA, Abd Al Shakour MY. Holothuria arenicola as a new antiseptic drug: In vitro antibacterial investigation and in vivo therapeutic role. Research Journal of Pharmaceutical, Biological and Chemical Sciences. 2015;6(5):366- 374.

21.Omran, NEE. Nutritional Value of Some Egyptian Sea Cucumber. African J Biotechnol. 2013;12(35):5466-5472.

22. Bordbar S, Anwar F, Saari N. High-Value Components and Bioactives from Sea Cucumbers for Functional Foods. Mar Drugs. 2011;9(10):1761-1805. doi: 10.3390/md9101761

23. Nartey ET, Ofosuhene M, Agbale CM. Anti-ulcerogenic activity of the root bark extract of the African laburnum "Cassia sieberiana" and its effect on the anti-oxidant defence system in rats. BMC Complement
Altern Med. 2012;10:247. doi: 10.1186/1472-6882-12-247

24. Tytgat GN. Etiopathogenetic principles and peptic ulcer disease classification. Dig. Dis. 2011;29(5): 454-458. DOI: 10.1159/000331520

25. Helpern GM. Nature"s safe and effective remedy for ulcers. Square one publisher, inc. consumer"s health. 2004, Eds., 1-165.

26. Tulassay Z, Herszényi L. Gastric mucosal defense and cytoprotection. Best Practice \& Research Clinical Gastroenterology. 2010;24(2): 99108. DOI: $10.1016 /$ j.bpg.2010.02.006

27. Ozbayer C, Kurt H, Ozdemir Z, Tuncel T, Moheb Saadat S, Burukoglu D et al. Gastroprotective, cytoprotective and antioxidant effects of Oleum cinnamomi on ethanol induced damage. Cytotechnology. 2014;66(3):431-441. DOI: 10.1007/s10616-013-9594-y

28. Choudhary M, Kumar V, Singh S. Gastric antisecretory an cytoprotective effects of hydroalcoholic extracts of Plumeria alba Linn. leaves in rats. J Integr Med. 2014;12(1): 42-51. DOI: 10.1016/S2095-4964(14)600029

29. Fahmy SR, Amer MA, Al-killidar MH. Ameliorative effect of the sea cucumber Holothuria arenicola extract against gastric ulcer in rats. The Journal of Basic \& Applied Zoology. 2015;72:16-25.

30. Nagar H, Tiwari P, Jain DK, Chandel HS. Evaluation of Anti-ulcer Activity of Stem Bark Extract of Aphanmixis Polystachya in Experimental Rats. Ind J Pharm Edu Res. 2012;46(3):222-227.

31. Tiwari DK, Tripathi RK, Jena J. Evaluation of antiulcer and antianxiety activity of Aphanamixis polystachya stem bark extract on rats Int. J. Pharm. Pharm. Sci. 2012;5:148-151.

32. Banji D, Singh J, Banji OJ. Scrutinizing the aqueous extract of leaves of pedalium murex for the antiulcer activity in rats. Pak J Pharm Sci. 2010;23(3):295-299.

33. Dial E, Thompson WJ, Rosenfeld GC. Isolated parietal cells histamine response and pharmacology. J Pharmacol Exp Therap.1981;219(3):586-590.

34. Qin HD, Shi YQ Liu ZH, Li ZG, Wang HS, Wang H, et al. Effect of chlorogenic acid on mast cell-dependent anaphylactic reaction. Int Immunopharmacol. 2010;10(9):1135-1141. DOI: 10.1016/j.intimp. 2010.06.018

35. Sabiu S, Garuba T, Sunmonu T, Ajani E, Sulyman A, Nurain I, et al. Indomethacin-induced gastric ulceration in rats: Protective roles of Spondias mombin and Ficus exasperate. Toxicology Reports. 2015;2:261-267.

36. Okajima K, Murakami K, Liu W, Uchiba M.. Inhibition of neutrophil activation by ranitidine contributes to prevent stress-induced gastric mucosal injury in rats. Crit Care Med. 2000;28(8):2858-2865.

37. Shimoyama AT1, Santin JR, Machado ID, de Oliveira e Silva AM, de Melo IL, Mancini-Filho J, et al. Antiulcerogenic activity of chlorogenic acid in different models of gastric ulcer. Naunyn Schmiedebergs Arch Pharmacol. 2013;386:5-14. DOI: 10.1007/s00210-012-0807-2

38. Zatorski H, Sałaga M, Zielińska M, Piechota-Polańczyk A, Owczarek K, Kordek R, et al. Experimental colitis in mice is attenuated by topical administration of chlorogenic acid. Naunyn Schmiedebergs Arch Pharmacol. 2015;388(6):643-651. DOI: 10.1007/s00210-015-1110-9

39. Kim JH, Kim BW, Kwon HJ, Nam SW. Curative effect of selenium against indomethacin-induced gastric ulcers in rats. Journal of Microbiology and Biotechnology. 2011;21(4):400-404.

40. Zhang Y, Song S, Liang H, Wang Y, Wang W, Ji A. Enhancing effect of a sea 
cucumber Stichopus japonicas sulfated polysaccharide on neurosphere formation in vitro. Journal of Bioscience and Bioengineering. 2010;110(4):479-486. DOI: 10.1016/j.jbiosc.2010.05.009

41. Ardestani SK, Janlow MM, Kariminia A, Tavakoli Z. Effect of cimetidine and ranitidine on lipid profile and lipid peroxidation in $\gamma$-irradiated mice. Acta. Med. Iran. 2004;42(3):198-204.

42. Moskaug JØ, Carlsen H, Myhrstad MC, Blomhoff R. Polyphenols and glutathione synthesis regulation. Am J Clin Nutr. 2 005;81(1suppl):277S-283S.

43. Althunibat OS, Hashim RB, Taher M, Daud JM, Ikeda M, Zali I. In vitro antioxidant and anti proliferative activities of three Malaysian sea cucumber species. Eur J Sci Res. 2009;37(3):376-387.

44. Park SW, Lee CH, Kim YS, Kang SS, Jeon SJ, Son KH, et al. Protective effect of baicalin against carbon tetrachloride-induced acute hepatic injury in mice. Journal of Pharmacological Sciences. 2008;106(1):136143.

45. Bessa SS, Mohamed Ali EM, Abd El-Wahab AE, Nor El-Din SA. Heme Oxygenase-1 mRNA Expression in Egyptian Patients With Chronic Liver Disease. Hepat Mon. 2012;12(4):278-285. Doi: 10.5812/ hepatmon.846

46. Awadallah AM, Issa HA, Soliman MS. Evaluation of Serum Chromogranin A as a Useful Tumor Marker for Diagnosis of Hepatocellular Carcinoma. Journal of American Science. 2011;7(1):999-1007.

47. Aydın S, Tokaç M, Taner G, Arıkök AT, Dündar HZ, Ozkardeş AB, et al. Antioxidant and antigenotoxic effects of lycopene in obstructive jaundice. J Surg Res. 2013;182(2): 285-295. DOI: 10.1016/j. jss.2012.10.031

48. Han JM, Kim HG, Choi MK, Lee JS, Park HJ, Wang JH, et al. Aqueous extract of Artemisia iwayomogi Kitamura attenuates cholestatic liver fibrosis in a rat model of bile duct ligation.Food ChemToxicol. 2012;50(10):3505-3513. DOI: 10.1016/j.fct.2012.07.018

49. Jüngst C, Berg T, Cheng J, Green RM, Jia J, Mason AL et al. Intrahepatic cholestasis in common chronic liver diseases. Eur J Clin Invest. 2013;43(10):1069-1083. DOI: 10.1111/eci.12128

50. Hofmann AF. Cholestatic liver disease: pathophysiology and therapeutic options. Liver Suppl. 2002; 2:14-19.

51. Lee TY, Chang HH, Chen JH, Hsueh ML, Kuo JJ. Herb medicine ameliorates hepatic fibrosis in bile duct ligation rats. J Ethnopharmacol. 2007;109(2):318-324. DOI: 10.1016/j.jep.2006.07.042

52. Feng Jin, Du Cheng, Jun-Yan Tao, Shu-Ling Zhang, Ran Pang, Yuan-Jin Guo, et al. Anti-inflammatory and anti-oxidative effects of corilagin in a rat model of acute cholestasis. BMC Gastroenterol. 2013;13:79.

53. Nasehi M, Tackallou SH, Hasani I, Nasehi M. Cholestasis impaired spatial and non-spatial novelty detection in mice. Journal of Paramedical Sciences. 2013;4(1):92-98.
54. Fuentes-Broto L1, Miana-Mena FJ, Piedrafita E, Berzosa C, Martínez-Ballarín E, García-Gil FA, et al. Melatonin protects against taurolithocholic induced oxidative stress in rat liver. J Cell Biochem. 2010;110(5):1219-1225. DOI: 10.1002/jcb.22636

55. Fahmy SR, Hamdi SA.. Curative effect of the Egyptian marine Erugosquillamassavensis extract on carbon tetrachloride-induced oxidative stress in rat liver and erythrocytes. Eur Rev Med PharmacolSci. 2011;15(3):303-312.

56. Awang D. Milk thistle. Can Pharm J. 1993;749-754.

57. Pastor A, Collado PS, Almar M, González-Gallego J. Antioxidant enzyme status in biliary obstructed rats: effects of $\mathrm{N}$-acetylcysteine. J Hepatol. 1997;27(2):363-370.

58. Wang JH, Liu YL, Li CL, Yu J, Wang F, Li X, et al. Effect of chlorogenic acid extracted from Eucommia Ulmoides Oliv on hyperlipemia of mice induced by high fat diet. Science and Technology of Food Industry. 2012;15:360-362.

59. Kumar R, Chaturvedi AK, Shukla PK, Lakshmi V. Antifungal activity in triterpene glycosides from the sea cucumber Actinopyga lecanora. Bioorg Med Chem Lett. 2007;17(15):4387-4391. DOI: 10.1016/j. bmcl.2006.12.052

60. Adibpour N, Nasr F, Nematpour F, Shakouri A, Ameri A. Antibacterial and antifungal activity of Holothuria leucospilota isolated from Persian Gulf and Oman Sea. Jundishapur, J. Microbiol. 2014;7(1). Doi: 10.5812/ jjm.8708

61. Shakouri A, Nematpour F, Adibpour N, Ameri A. Environmental Studies of Persian Gulf. Environmental studies of Persian Gulf. 2014;7:135140 .

62. Dhinakaran DI, Lipton AP. Bioactive compounds from Holothuria atra of Indian Ocean. International Journal of Biology and Biological Sciences. 2014;3:6-11. Doi: 10.1186/2193-1801-3-673

63. Lee SE, Hwang HJ, Ha JS, Jeong HS, Kim JH.. Screening of medicinal plant extracts for antioxidant activity. Life Sci 2003;73(2):167-179.

64. Seely KA, Holthoff JH, Burns ST, Wang Z, Thakali KM, Gokden N, et al. Hemodynamic changes in the kidney in a pediatric rat model of sepsis-induced acute kidney injury. Am J Physiol Renal Physiol. 2011;301(1):F209-F217. DOI: 10.1152/ajprenal.00687.2010

65. Harrison M, Collins CD. Is Procalcitonin-Guided Antimicrobial Use Cost-Effective in Adult Patients with Suspected Bacterial Infection and Sepsis? Infect Control Hosp Epidemiol. 2015; 36(3):265-272. DOI: 10.1017/ice.2014.60

66. Li H, Luo YF, Blackwell TS, Xie CM. Meta-analysis and systematic review of procalcitonin-guided therapy in respiratory tract infections. Antimicrob Agents Chemother. 2011;55(12):5900-5906. DOI: 10.1128/AAC.00335-11 